\title{
Training for Cost-Effectiveness vs. Training as Tax Evasion Tool - A Study on Selected Private Companies in Bangladesh
}

\author{
Tanjela Hossain ${ }^{1 *}$, Md. Asad Noor ${ }^{2}$
}

${ }^{1}$ Senior Lecturer in HRM, Department of Business Administration, Central Women's University, Dhaka, BANGLADESH

${ }^{2}$ Senior Lecturer in Finance, Green Business School, Green University of Bangladesh, Dhaka-1207, BANGLADESH

*Corresponding Contact:

Email: tanjela.hossain@gmail.com

DOI: https://doi.org/10.18034/gdeb.v7i1.103

\begin{abstract}
Bangladeshi organizations consider employee training as an indispensable strategic tool for enhancing employee's performance. Although training seems to be an expense, it is regarded as an investment. Every company is increasing the amount of the budget on training programs showing the reason that training brings the competitive edge. The study is focused on analyzing the tendency of increasing the training budget to know whether it is an investment or an evasion medium of tax in Bangladesh. A survey has been administered to find the degree of effectiveness of training programs, the utilization of budget on training, the cost-effectiveness of training programs and the possibility of training programs used as a tax evasion medium in Bangladesh. We have collected data through a semi-structured questionnaire from a sample of 200 employees working in 20 private organizations located in Dhaka city. We have observed from our survey that most of the time training programs held in different organizations in Bangladesh are not always effective. Trainees are not getting the most out of it. Contrary to the expectation, the analysis showed that the training budget is not sufficient. Although companies are increasing the amount of the training budget every year, it is not enough to give best results. And the budget is not utilized effectively in many cases. For this, many company's performance in costeffectiveness of training is not satisfactory. The formal evaluation method is not followed in every company, and the training programs are not improved always. Every organization doesn't conduct cost and benefit analysis of training programs. The study has also found that training can be used as a tax evasion tool and in many organizations, it is somewhat being used. Training program opens up the opportunity to include false expenses which increases the total cost. The result of increased expense is a decrease in taxable profit. We have used mean, standard deviation, variance, percentage analysis, hypothesis testing, etc. for statistical analysis.
\end{abstract}

Key Words: Training, tax evasion, cost-effectiveness, budgeting 


\section{INTRODUCTION}

Although training is considered as an indispensable strategic tool for enhancing employee performance for the development of the organization, is it being used or misused as a tax evasion tool in Bangladesh? This question arises because organizations keep increasing training budget on a yearly basis showing the reason that it would earn them the competitive edge. Is the increased budget for training cost effective?

Organizations nowadays hire and get the most capable new person who suits the vacant job. Basic orientation program and on the job training ought to be quite enough for these new comers. As the employee becomes capable of doing the job and can do it by the help of on the job training, is there a vast need for off the job training? Is off the job training really beneficial and will earn competitive edge for the company?

While conducting a training program, the company gets opportunity to make unnecessary costing in several accounts, include bogus or false transactions and also to record excess expenses. These attempts increase the costs and reduce the taxable profit. Another possible way can be when a director of a company hires expensive trainers and train the employee the fee of the trainer becomes a cost of the company. So, are the companies using these tools to evade tax, for which they are emphasizing on training programs and increasing their budget for training programs every year?

Many scholars showed that training programs are arranged as an investment for future development even though it seems to be an expense for current time. But there might be a question arise in the context of Bangladesh, is it a successful investment as most of the time training need assessment are not conducted? Training programs are known to have multidimensional effects on employees. It increases productivity by improving skills, technologies, knowledge, and know-how. It also improves employee performance by reducing errors. Training programs introduce the company to the employees and motivate them to be loyal. It also enhances and develops team performance and leadership skills. Well trained employees reduce the rate of turnover. Training is also a medium of strengthening employee relationship. And it increases the satisfaction level of employees as they perform well in their jobs with the help of training. But what actually happen in the private companies of Bangladesh?

So, our research is focused on seeking the answers of the above questions. Actually, the main fact is we want to know whether private organizations are using training program as a tax evasion tool or not in Bangladesh.

\section{Research Objectives}

The primary objective of the study is to understand the cost-effectiveness of increased budget on training in some selected private ltd. company of Bangladesh and to know whether organizations are using training as a tax evasion tool or not. Specifically, the study seeks:

- To examine the effectiveness of training programs in the mentioned companies of Bangladesh.

- To know whether the training programs are being cost-effective or not in regard to the increased budget on training.

- To find out the relationship between cost-effectiveness of training programs and tax evasion.

- To analyze the possibility of training programs being used as tax evasion tool.

- To know whether private organizations are using training programs as tax evasion tool or not. 


\section{Research Questions}

This research attempts to discover answers to the questions regarding the cost-effectiveness of training programs in Bangladesh and also whether training is being used as a tax evasion tool or not by the companies of Bangladesh. The study answers the following research questions:

- Is training truly being beneficial in Bangladesh? What is the real scenario?

- Are the companies properly utilizing the budget for training?

\section{LITERATURE REVIEW}

\section{The Effectiveness of Training Programs}

Experts agree that training programs are essential to the success of all companies. Studies have shown that training has been linked to improved self-esteem, reduced turnover, better product and service consistency, higher guest satisfaction, reduced business costs, the use of new technology, greater ability to meet the needs of a target market, more qualified employees, increased self-awareness, improved attitude, more teamwork, greater job satisfaction and greater organizational commitment (Roehl \& Swerdlow, 1999, p. 176). Training has also been shown to attract new employees (Conrade etal., 1994, p. 17). Walsh and Taylor (2007) suggest that individuals can become emotionally or economically committed to their companies; those who are emotionally committed are loyal to their organizations and identify with its goals and missions, while those who are economically committed engage in a resource exchange with their organization (p. 165). Ely (2009) found training to be a competitive edge and lead to better employee retention. Firms undertaking higher levels of training also had a positive attitude that training leads to success; they had integrated training as a part of strategy, adopted training that is very practical rather than theoretical; and acknowledged the importance of strategic role for training (Butcher etal., 2009, p. 389-90). Roehl and Swerdlow (1999) also found that there was a positive relation between morale, the perception of supervisor quality, and awareness of rules regardless of tenure of employees in the organization (p. 190). Furthermore, a major purpose of training is to help a company compete more effectively in its present situation and in the future; training cannot be isolated from strategic business planning or disconnected from the company's product, its market situation, or management of its corporate identity (Haywood, 1992, p. 49). Continuous training can also make knowledge, skills and behaviors a working part of a person's day (Ely, 2009).

\section{Cost-effectiveness of training programs \& evaluation methods}

Companies are constantly looking for methods in which to measure and evaluate the cost effectiveness of training. According to Tracey and Tews (1995), the traditional view of training includes a formal assessment of training needs, use of appropriate training methods, and an evaluation of the training program (p. 37). Enz and Siguaw (2000, Oct) found that "companies with successful training programs emphasized the importance of getting employees involved early in the process, rolled out the program gradually to gain employee support, and provided proper training and sufficient empowerment to allow employees to excel in their jobs" (p. 29).

Some companies are using return on investment (ROI) as another method to measure the effectiveness of their training programs. To measure ROI, some companies look at the consequences of not training, other use performance records and cost/benefit analysis (Rowden, 2001, p. 6). Kirkpatrick's four-level model deals with ROI in the third and fourth 
levels, behavior and results; in fact, Kirkpatrick believes that "the most desirable approaches to delivering instruction (training) are those that are the most effective in terms of results and the most efficient in terms of cost" (Rowden, 2001, p. 7). According to Rowden (2001), there are two ways of calculating ROI - calculating the cost-benefit ratio and the ROI. The cost benefit ratio is calculated by dividing the total benefits by the cost while the ROI subtracts costs from the total benefits to produce the net benefits, which are then divided by the costs. To further the calculation of ROI, Philips (1996, Feb) developed a model that built upon Kirkpatrick's, in which training costs would be compared with monetary benefits but would assume that all training programs would have intangible, but reportable, benefits ( $\mathrm{p}$. 43). By measuring ROI, it provides goals for the progress of all training of a particular segment, as well as focusing attention on accountability and the need for measurement and evaluation (Phillips, 1996, Feb, p. 44). Moreover, by calculating ROI in a recessionary period, companies may find that "a particular training program enables a team to perform tasks in less time or with fewer members" (Phillips, 1996, Apr, p. 22). Another method that companies can use to measure training effectiveness is through total quality management (TQM). According to Baldacchino (1995), TQM directs the efforts of professional management towards a corrective, educational and empowering relationship with their subordinates by rewarding and reinforcing individual employee's positive performance, by providing various opportunities for skills training and retraining (p. 69). There are five quality checkpoints that TQM uses to recognize product or service quality - determining how well a product or a service meets customers"e needs and wants; inspecting the product or service prior to customer delivery; controlling quality during production; assessing quality of raw materials prior to production; and examining the suppliers" quality control procedures (Partlow, 1996, p. 68-69). By incorporating TQM into the company's management style, attitudes will need to change from traditional disciplinary and inspectorial function to a supportive, preventive and facilitative one (Baldacchino, 1995, p. 71). Communication is a key component to successful TQM as employees can observe management and their emphasis on consistency in service quality as well as management's sincerity in listening to employees' opinions (Partlow, 1996, p. 70-71). One must note however that training programs may not take into consideration an employee's motivation, his or her ability to learn and acquire knowledge and skills as well as an employee's attitude towards his or her work can affect the training program's effectiveness (Tracey \& Tews, 1995, p. 39-40). Harris (2007) believes that it is impossible to have complete accuracy when measuring ROI due to the variability of human factor, timeliness of information, and accuracy of all information (p. 490). Therefore, Tracey and Tews (1995) suggest that trainers should understand these variables when developing training programs, thereby enhancing training efforts (p. 42). In addition, companies should ask learners themselves what the training program is lacking (Weinstein, 2009, p. 106). For example, Phillips (1996, Mar) proposes the following methods as ways for companies to measure its training's effects on performance - use of control groups, trend-line analysis, forecasting, participation estimation, supervisor estimation, management estimation, customer input, expert estimation and subordinate input (p. 30-32). These methods should act as guidelines for ROI and although the figures will not be precise, they will give the best estimates given the conditions, time and resources a company will commit (Phillips, 1996, Mar, p. 32). In their study, Frash etal. (2008) found that the learning outcome of a training participant has more value than knowing whether or not the participant like the training, and that the more the participants enjoyed the training, the greater the learning outcome will be (p. 213-214). 


\section{TAX AvoIDANCE AND Evasion}

The general public uses these two terms interchangeably, but there is a definite distinction according to Lowe and Wright. Avoidance is the use of specific exemptions, exclusions and deductions allowed by law. Evasion on the other hand, is an attempt to clothe Illegal deductions with a semblance of legality. Prebble and Prebble (2010) describes evasion and avoidance as factually similar but legally distinct. While they are motivated by the same desire to reduce tax liability, they have different legal classifications. Furthermore, the economic outcomes of the two are identical; both result in a reduction in taxes, but do so in different ways. Tax evasion is illegal and often criminal. According to Black's Law Dictionary (9th ed. 2009) evasion is "the willful attempt to defeat or circumvent the tax law in order to illegally reduce one's tax liability." Tax evasion occurs when a taxpayer's transactions result in a certain amount of taxable income, but the taxpayer declares a lower income on their return, or fails to make a return at all (Prebble 1996).

According to Black's Legal Dictionary avoidance is "the act of taking advantage of legally available tax-planning opportunities in order to minimize one's tax liability." Unlike evasion, avoidance is not criminal, and is often said to be legal. Avoidance exploits the tax law to use it in a way unintended by parliament by following its black letter requirements but not its spirit (IRC v Willoughby, 1997).

\section{Research Methodology}

The research has made extensive use of both primary and secondary data. We have collected all the primary data by administering a questionnaire to respondents in the selected companies. Interviews have also been conducted to access the information about the training programs, budget on training and tax evasion.

\section{The population of study}

The population of the study is all of the private ltd companies of Bangladesh who offer training programs. As it is not possible to cover all private ltd. companies of Bangladesh under a survey, a sample survey was conducted in this study.

\section{The Sample Selection and Sample Size}

We were selected the sample companies through convenience sampling and judgment or purposive sampling method. Some companies were taken where it was possible to gain access to the information and the personnel who were interested in helping with the study. It was tried to cover as many types of companies as possible. Thus, companies such as bank, NGO, medical equipment dealing company, outsourcing company, production-oriented company, and service-oriented company were targeted for sampling. In total there are 20 (twenty) companies which were chosen as sample. The sub-sample size is 200 employees from 20 companies, to whom the survey was administered.

\section{Research Instrument}

A questionnaire was used for collecting responses from the subject selected for the study. In total there are 18 fixed-alternative checklist questions and a personal information section.

The questionnaire contained two parts. One part was on personal information from which demographic information such as name, profession, organization, training experience, etc. could be known. 
Another part was used to measure the effectiveness of training, cost-effectiveness of training, the relationship between utilization of training budget and tax evasion and training programs used as a tax evasion tool by asking five-point Likert-type-scale questions. Respondents were asked to indicate whether they strongly agree or Strongly disagree with each statement using a five-point Likert-type scale. Responses for these questions ranged from $1=$ Strongly disagree, $2=$ Disagree, $3=$ Neutral, $4=$ Agree, $5=$ Strongly agree .

\section{Data Collection Procedure}

An open discussion, observation of activities and a survey were done to gather information from the people working in private organizations of Bangladesh. From the 20-private ltd. company's 200 respondents were interested in the study. We have taken 50 employees' personal interview and other 150 employees were surveyed thorough e-mail. There were many more questionnaires un-answered which were sent via e-mail to employees.

To make the Study more meaningful and presentable, secondary sources of data and information have been used extensively. The sources are-

The Secondary Sources are as follows:

- Office files and documents.

- Study-related books and journals.

- Reports on Training and tax evasion.

- Official websites of the related companies.

- Other information provided in different websites.

\section{Data Processing \& Analysis}

Upon completion of the survey, a quantitative approach has been taken to analyze the data. The data was first entered on IBM SPSS Statistics (22) program for further analysis. With the help of SPSS and MS Excel, raw data from the questionnaire could be processed through frequency and descriptive statistics to get meaningful information. To measure the data, an ordinal scale has been used. The gathered information regarding the qualitative part was processed \& compiled with the aid of MS Word and necessary tables, detailed interpretation and analysis have also been incorporated in the Study.

\section{Data ANALysis AND REsult}

The study was intended to know whether training programs in Bangladesh are costeffective or not and whether increasing budget on training programs is an investment to improve employee performance or a tax evasion medium. To know the answers of these questions, the questionnaire was made to collect responses on three significant issues. Those issues are-

- The effectiveness of training programs in private ltd. companies in Bangladesh.

- Cost-effectiveness of training programs regarding to the proper utilization of the increased budget on training programs.

- Training as a successful investment or a tax evasion medium.

Respondents were asked a series of open questions, semi-open questions, multiple choice questions, dichotomous questions. Findings and Analysis are presented below based on the questions of the questionnaire used in this study. 


\section{The demographic profile of the respondents:}

At the very beginning of our data collection, we classify the respondents by their gender, level of job, job experience and number of training program they have undergone.

Table 1: Demographic factors of the respondents

\begin{tabular}{|l|c|c|}
\hline Demographic factors & No. of Respondents & Percentage (\%) \\
\hline \multicolumn{3}{|c|}{ Gender } \\
\hline a) Male & 112 & $56 \%$ \\
\hline b) Female & 88 & $44 \%$ \\
\hline \multicolumn{3}{|c|}{ Level of job } \\
\hline Top Level & 35 & $17.5 \%$ \\
\hline Mid-Level & 56 & $28 \%$ \\
\hline Entry Level & 109 & $54.5 \%$ \\
\hline \multicolumn{3}{|c|}{ Experience } \\
\hline Less than a year & 37 & $18.5 \%$ \\
\hline 1 year -4 years & 83 & $41.5 \%$ \\
\hline 4 years -7 Years & 45 & $22.5 \%$ \\
\hline More than 7 years & 35 & $17.5 \%$ \\
\hline \multicolumn{3}{|c|}{ No. of training undergone } \\
\hline a) None & 18 & $9 \%$ \\
\hline b) 1-3 times & 97 & $48.5 \%$ \\
\hline c) 4-7 times & 34 & $17 \%$ \\
\hline d) 7-10 times & 29 & $11 \%$ \\
\hline e) 10 above & 22 & \\
\hline
\end{tabular}

Table 1 highlights that most of the respondents were male $56 \%$ of our 200 employees and $44 \%$ of 200 respondents were female. The table also indicates that $18.5 \%$ of the respondents had experience less than one year, $41.5 \%$ had experience between $1-4$ years, $22.5 \%$ of the respondents had 4-7 years of experience and the rest $17.5 \%$ hold more than 7 years of experience. In this study, most of the employees are (54.5\%) at entry level, $28 \%$ are at Midlevel and $17.5 \%$ are at top level of management. It is also clear from the table that $9 \%$ of 200 respondents never go for training, $48.5 \%$ have undergone between 1-3 times, $17 \%$ for between 4-7 times, $14.5 \%$ for between, and only $11 \%$ of respondents have gone for more than 10 times.

\section{Analysis of Effectiveness of Training Programs}

To learn about the effectiveness of training programs many questions were asked to the respondents. The questions were fixed-alternative checklist questions. On the questionnaire, question number- $5,6,7,8,9,10,11$, and 12 are the questions used to measure the effectiveness of training programs. Except for number 5, all other questions are Five-point Likert-type scale. The scales are - Strongly Disagree to Strongly Agree, numbered in 1 to 5 respectively.

The frequencies found by using SPSS program from the above numbered ordinal scale questions are shown in the following Table 2.

From the table 2, the average of mean and std. deviation can be known. The composite mean is 3.259 and std. deviation is 1.06 derived from the 7 questions on the effectiveness of training programs. These values mean that the effectiveness of training falls around (3.259- 
$1.06)$ to $(3.259+1.06)$, which is- 2.199 to 4.319 on the five-point scale. On the scale, 1 was given Strongly Disagree, 2 was given to Disagree, 3 was given to Neutral and 4 was given to Agree, 5 was given to Strongly Agree. So, the answer to whether training was effective or not falls mostly between Disagree (Somewhat Agree) to Agree.

Table 2: Effectiveness of Training Programs

\begin{tabular}{|l|l|c|c|c|}
\hline No. & \multicolumn{1}{|c|}{ Question Statement } & Mean & Standard Deviation & Variance \\
\hline Q.6 & $\begin{array}{l}\text { There is noticeable development in job } \\
\text { performance after training. }\end{array}$ & 3.605 & 1.116 & 1.245 \\
\hline Q.7 & $\begin{array}{l}\text { Training improves the overall performance of an } \\
\text { organization. }\end{array}$ & 3.865 & 0.928 & 0.861 \\
\hline Q. 8 & Training reduces errors/wastage & 3.775 & 1.127 & 1.271 \\
\hline Q.9 & $\begin{array}{l}\text { Trainers are well competent and can get across } \\
\text { their ideas. }\end{array}$ & 3.59 & 1.126 & 1.268 \\
\hline Q. 10 & $\begin{array}{l}\text { Training needs are identified through some } \\
\text { specific mechanism in your organization. }\end{array}$ & 2.585 & 0.904 & 0.817 \\
\hline Q. 11 & $\begin{array}{l}\text { There are formal training evaluation methods to } \\
\text { assess the effectiveness of the training }\end{array}$ & 2.785 & 1.032 & 1.064 \\
\hline Q. 12 & $\begin{array}{l}\text { Training programs are periodically evaluated and } \\
\text { improved. } \\
\text { Composite Mean }\end{array}$ & 2.605 & 1.186 & 1.406 \\
\hline
\end{tabular}

Comment on the degree to which the training objectives are met during the training sessions.

Here we tried to find out the degree to which the training objectives are met during the training sessions from the data collected under question-5. A simple percentage analysis was administered in the following table 3.

Table 3: Degree to Training Objectives

\begin{tabular}{|l|l|c|c|}
\hline No & \multicolumn{1}{|c|}{ Factors } & No. of respondents & Percentage $\%$ \\
\hline 1. & All Objectives & 9 & $4.5 \%$ \\
\hline 2. & Some Objectives & 53 & $26.5 \%$ \\
\hline 3. & According to Need & 138 & $69 \%$ \\
\hline 4. & None & 0 & $0 \%$ \\
\hline & Total & $=200$ & $=100 \%$ \\
\hline
\end{tabular}

Only 9 out of 200 respondents answered that all objectives of the training programs were met. Nearly half of the total number answered that objectives were met according to the need. Rest of the respondents chose that some objectives were met. It shows that many times, training objectives are not properly met.

Analysis of Cost-effectiveness of training programs regarding the proper utilization of the increased budget on training:

To learn about the cost-effectiveness of training programs three questions were asked to the respondents. On the questionnaire, question number-13,14 and 15 are the questions used to measure the cost-effectiveness of training programs and the proper utilization of the increased budget on training programs. All questions are five-point Likert-type-scale. The scales are- Strongly Disagree to strongly agree, numbered in 1 to 5 respectively. 
The frequencies found by using SPSS program from the above numbered ordinal scale questions are shown in the following Table 4.

Table 4: Frequencies in the cost-effectiveness of training programs on proper utilization

\begin{tabular}{|l|l|c|c|c|}
\hline No. & \multicolumn{1}{|c|}{ Question Statement } & Mean & Standard Deviation & Variance \\
\hline Q. 13 & $\begin{array}{l}\text { The organization has a system for calculating } \\
\text { the cost and benefit of training programs. }\end{array}$ & 2.53 & 1.046 & 1.095 \\
\hline Q. 14 & $\begin{array}{l}\text { The budget for training is sufficient in your } \\
\text { organization }\end{array}$ & 2.92 & 1.014 & 1.029 \\
\hline Q. 15 & $\begin{array}{l}\text { The budget for training is effectively and } \\
\text { efficiently utilized. }\end{array}$ & 2.495 & 1.075 & 1.156 \\
\hline & Composite Mean & 2.648 & 1.045 & 1.093 \\
\hline
\end{tabular}

The composite mean is 2.648 and std. deviation is 1.045 derived from the 3 questions on the costeffectiveness of training programs. So, the cost-effectiveness of training falls around (2.648-1.045) to $(2.648+1.045)$, which is- 1.603 to 3.69 on the five-point scale. So, the answer to whether training is cost effective or not falls mostly between Disagree (Somewhat agree) to Neutral.

\section{Analysis on the Relationship between Cost Effectiveness of the Increased Budget and Tax Evasion}

On the questionnaire, number 14, 16, 17 were asked to know about the relationship between cost effectiveness of the increased budget and tax evasion. It was tried to learn about the sufficiency of the budget on training, whether organizations keep increasing the budget for training every year or not and whether training programs are used as a tax evasion tool. All questions are five-point Likert-type-scale. The scales are- Strongly Disagree to Strongly Agree, numbered in 1 to 5 respectively.

The frequencies found by using SPSS program from the above numbered ordinal scale questions are shown in the following table 5.

Table 5: Frequencies in the Cost Effectiveness of the Increased Budget and Tax Evasion

\begin{tabular}{|c|l|c|c|c|}
\hline No. & \multicolumn{1}{|c|}{ Question Statement } & Mean & Standard Deviation & Variance \\
\hline Q.14 & $\begin{array}{l}\text { The budget for training is sufficient in your } \\
\text { organization }\end{array}$ & 2.92 & 1.014 & 1.029 \\
\hline Q.16 & $\begin{array}{l}\text { Your organization keeps increasing the budget } \\
\text { for training every year. }\end{array}$ & 3.62 & 1.11 & 1.232 \\
\hline Q.17 & $\begin{array}{l}\text { Organizations use training programs as a tax } \\
\text { evasion tool by increasing the cost. }\end{array}$ & 3.825 & 1.058 & 1.12 \\
\hline & Composite Mean & 3.455 & 1.060 & 1.127 \\
\hline
\end{tabular}

From the composite values of the mean and std. deviation, a generalized answer can be found. The composite mean is 3.455 and std. deviation is 1.060 derived from the 3 questions. So, the generalized answer falls around (3.455-1.060) to (3.455+1.060), that is- 2.395 to 4.515 on the four-point scale. So, the answer falls mostly between Disagree (somewhat agree) to Agree.

\section{Association between Arranging Training Program and Occurrence of Tax Evasion}

Here we try to find out the relationship between the arrangement of training program and Occurrence of tax evasion by using Chi-Square analysis. 
Null Hypothesis: There is no significant relationship between the arrangement of training program and Occurrence of tax evasion

Alternate Hypothesis: There is a significant relationship between the arrangement of training program and Occurrence of tax evasion

Table 6: Scenario between the relationship between the arrangement of training program and Occurrence of tax evasion

\begin{tabular}{|c|c|c|c|c|}
\hline \multicolumn{2}{|c|}{} & \multicolumn{2}{|c|}{ Tax Evasion } & \multirow{2}{*}{ Total } \\
\cline { 3 - 5 } \multicolumn{2}{|c|}{ Training Program } & Yes & No & \\
\cline { 2 - 4 } & No & 95 & 26 & 121 \\
\hline \multicolumn{2}{|c|}{ TOTAL } & $=142$ & $=58$ & 79 \\
\hline
\end{tabular}

Table 7: Calculated Chi-Square value and Table Value

\begin{tabular}{|c|c|c|c|c|c|}
\hline $\begin{array}{c}\text { Sl. } \\
\text { No }\end{array}$ & Factor & $\begin{array}{c}\text { Calculated } \\
\mathrm{X}^{2} \text { Value }\end{array}$ & $\begin{array}{c}\text { Degree of } \\
\text { Freedom }\end{array}$ & $\begin{array}{c}\text { Table } \\
\text { Value }\end{array}$ & Remarks \\
\hline 1. & $\begin{array}{c}\text { Training programs } \\
\text { \& tax evasion }\end{array}$ & 8.3963 & 1 & 3.84 & $\begin{array}{c}\text { Calculated } \mathrm{X}^{2} \text { value is more than the } \\
\text { Table value and the null hypothesis is } \\
\text { rejected }\end{array}$ \\
\hline
\end{tabular}

Table 6 and Table 7 shows the calculated value 8.3963 is more than the table value at $5 \%$ level of significance. So, the null hypothesis is rejected. Hence there is no relationship between the arrangement of training program and Occurrence of tax evasion.

\section{Scenario of Trainers for Training}

Question number 18 was asked directly to the respondents to know Trainers by whom the training programs are conducted. A simple percentage analysis was administered in the following table 8 .

Table 8: Trainers Experiences and Skills

\begin{tabular}{|c|l|c|c|}
\hline No & \multicolumn{1}{|c|}{ Trainer's Category } & No. of respondents & Percentage $\%$ \\
\hline 1. & Top Level Employees & 8 & $4 \%$ \\
\hline 2. & Skilled employees of your organization & 45 & $22.5 \%$ \\
\hline 3. & Professional trainers hired from Outside & 147 & $73.5 \%$ \\
\hline & Total & $=200$ & $=100 \%$ \\
\hline
\end{tabular}

The trainers are mostly the skilled professional trainers hired by the organization. But a few companies also use their expert employees to conduct the training program. But there are only few respondents answering that the trainer is the top-level employees of the organization.

It indicates that the owning bodies of the companies are conducting training to evade tax and make some benefits.

\section{Employee's Perceptions about the need for training}

Here we tried to find out the perception of employees about the requirement of organizational Training (Question no. 2), barriers to training (Question no 3), common complaint against training (Question no 4). A simple percentage analysis was administered in the following table $9,10,11$ respectively. 
Table 9: Need for Training Program

\begin{tabular}{|c|l|c|c|}
\hline No & \multicolumn{1}{|c|}{ Factors } & No. of respondents & Percentage \% \\
\hline 1. & To get promotions & 96 & $48 \%$ \\
\hline 2. & $\begin{array}{l}\text { To get yourself updated for new technologies/skills } \\
\text { and implement them }\end{array}$ & 88 & $44 \%$ \\
\hline 3. & Others & 11 & $5.5 \%$ \\
\hline 4. & Don't need training at all & 5 & $2.5 \%$ \\
\hline & Total & $=200$ & $=100 \%$ \\
\hline
\end{tabular}

Table shows that $48 \%$ of total respondents believe that they need to attend training for getting their promotion, $44 \%$ want training for being updated. Very few responds no for training and some give their comments in other sections. However, significant comments enrich our survey findings.

Table 10: Obstacle for Arranging Training

\begin{tabular}{|c|l|c|c|}
\hline No & Factors & No. of respondents & Percentage $\%$ \\
\hline 1. & Time & 33 & $16.5 \%$ \\
\hline 2. & Money & 94 & $47 \%$ \\
\hline 3. & Lack of interest of management & 67 & $33.5 \%$ \\
\hline 4. & Others & 6 & $3 \%$ \\
\hline & Total & $=200$ & $=100 \%$ \\
\hline
\end{tabular}

From the above table, it can be said easily that money is one of the major obstacle for arranging training. Nearly half $47 \%$ of the respondents responded for "Money" as obstacle.

Table 11: Employee Perceives Training

\begin{tabular}{|c|l|c|c|}
\hline No & \multicolumn{1}{|c|}{ Factors } & No. of respondents & Percentage $\%$ \\
\hline 1. & Takes away precious time & 37 & $18.5 \%$ \\
\hline 2. & Training sessions are unplanned & 93 & $46.5 \%$ \\
\hline 3. & Boring and not useful & 46 & $23 \%$ \\
\hline 4. & Causes Cost & 19 & $9.5 \%$ \\
\hline 5. & Others & 5 & $2.5 \%$ \\
\hline & Total & $=200$ & $=100 \%$ \\
\hline
\end{tabular}

From above table, it is clear that employee perceives training as Unplanned and Unstructured. $23 \%$ of 200 employees respond training as boring and useful too.

\section{SUMMARY OF FINDINGS}

The study revealed some findings on whether training programs in Bangladesh are cost-effective or not and whether increasing budget on training programs is an investment or a tax evasion medium.

In Bangladesh, the training programs lack many attributes which hampered the effectiveness of training programs. From the survey, it is found that training programs in private ltd. companies ranged from "somewhat effective" to "effective". In an average, calculated from the composite mean of the responses, it can be said that the training programs are almost effective. It is a good amount of effectiveness but not full. The major obstacles to the effectiveness of training are the absence of formal training evaluation methods to assess the effectiveness of training programs and the absence of periodical evaluation and improvement of the training programs. The training budget is somewhat sufficient, which is meant to be a lower degree of sufficiency. "Somewhat sufficient budget" is another obstacle to the effectiveness of the training programs. Studies also showed that most of the trainers are the professional trainer. It also hinders the effectiveness of training programs as the outsiders may not be known well about the employees need or lacking. 
As training programs are not being fully effective, it is not being able to serve the supreme competitive edge to the private ltd. companies of Bangladesh. The cost-effectiveness of the training programs is found to be very poor. From the survey, it is found that the respondents chose from the degree of disagree to neutral against the question of the cost-effectiveness of training programs. From the composite mean, it was found that training programs poorly cost effective. The budget on training is not sufficient, the budget is not being properly utilized and the organization is lacking the system for calculating the cost and benefit of training programs. The relationship between increased budget and tax evasion answered by the respondents fall in the range between disagree to agree. It means, most of the cases these two issues are not related to each other, but in little the evidence is found to have a relationship between increased budget and tax evasion. Result of Hypothesis testing clearly indicates that there is a significant relationship between the arrangement of training programs and the occurrence of Tax Evasion.

It can be said from the study that many companies may misuse training programs as a tax evasion medium. These companies possibly overestimate the costs and includes bogus or false entries of expenses on the account of training programs to increase the cost and use it as a medium to lessen or evade the tax. There are some other findings from this study. Most of the respondents think that they need training to effectively learn new technologies or skills and to properly implement them. The important barriers to training, as stated by the respondents, are time, money and willingness of the management. By time barrier, they indicated that on training there are a lot to learn within a very short period of time. Most of them either cannot understand the idea properly or forget. They also complain that the training programs are unplanned.

\section{Conclusion ANd ReCOMmendations}

From the study, it could be known that training is regarded as an indispensable strategic tool for enhancing employee performance for the development of the organization. The expense done on training should be considered as an investment which brings positive and cost-effective outcomes for the organization. These outcomes can be achieved only when the training programs are fully effective. All the objectives of the training programs must be met, the budget on the training programs should be sufficient and there should be professional trainers to conduct the training session. In Bangladesh, training programs are not being fully effective due to many reasons. One of the major reason is that the absence of evaluation and improvement of training programs. Insufficient budget, non-professional trainers, unplanned sessions are also hindering the effectiveness of training programs. The training programs are also not cost effective. Sometimes Companies misuse training programs as a tax evasion medium. By increasing the costs expended and recording fake expenses, costs are increased to minimize the taxable profit. Most of the private ltd. companies in Bangladesh are not being able to get the most out from the training programs. In spite of increasing the budget for training every year, the budget still is not sufficient to meet the objectives. Thus, the programs are not being cost effective. Training programs open up huge opportunity to include fake expenses which enables to evade tax.

\section{ReFERENCES}

Baldacchino, G. (1995). Total quality management in a luxury hotel: A critique of practice. International Journal of Hospitality Management, 14(1), 67-78.

Black's Law Dictionary (9th ed. 2009).

Butcher, K., Sparks, B., \& McColl-Kennedy, J. (2009). Predictors of customer service training in hospitality firms. International Journal of Hospitality Management, 28(3), 389396.

Conrade, G., Woods, R. H., \& Ninemeier, J. D. (1994). Training in the U.S. lodging industry: perception and reality. Cornell Hotel and Restaurant Administration Quarterly, 35(3), 16-21.

Ely, J. (2009, Sep 11). Training: The race is never over. Hotel and Motel Management. Retrieved from http:/ /www.hotelworldnetwork.com/ 
Enz, C. A., \& Siguaw, J. A. (2000, Oct). Best practices in service quality. Cornell Hotel and Restaurant Administration Quarterly, 41(5), 20-29.

Frash Jr., R., Kline, S., Almanza, B., \& Antun, J. (2008). Support for a multi-level evaluation framework in hospitality training. Journal of Human Resources in Hospitality \& Tourism, 7(2), 197-218.

Harris, K. J. (2007). Calculating ROI for training in the lodging industry: Where is the bottom line? International Journal of Hospitality Management, 26(2), 485-498.

Haywood, K. M. (1992). Effective training: Toward a strategic approach. Cornell Hotel and Restaurant Administration Quarterly, 33(4), 43-52.

IRC v Willoughby [1997] 1 WLR 1071.

Kirkpatrick, D. (1996). Great ideas revisited. Training and Development, 50(1), 54-59.

Partlow, C. G. (1996). Human-resources practices of TQM hotels. Cornell Hotel and Restaurant Quarterly, 37, 67-77.

Phillips, J. J. (1996, Apr). How much is the training worth? Training and Development, 50(4), 20-24

Phillips, J. J. (1996, Feb). ROI: The search for the best practices. Training and Development, 50(2), 42-47.

Phillips, J. J. (1996, Mar). Was it the training? Training and Development, 50(3), 28-32

Prebble, John "Criminal Law, Tax Evasion, Shams, and Tax Avoidance: Part I Tax Evasion and General Doctrines of Criminal Law" 19962 NZ J Tax L \& Policy 1

Prebble, John and Prebble, Zoe • \The Morality of Tax Avoidance. (2010) 20 Creighton L Rev 101

Roehl, W. S., \& Swerdlow, S. (1999). Training and its impact on organizational commitment among lodging employees. Journal of Hospitality \& Tourism Research, 23(2), 176-194.

Rowden, R. W. (2001). Exploring methods to evaluate the return on investment from training. American Business Review, 19(1), 6-12.

Tracey, J. B., \& Tews, M. J. (1995). Training effectiveness: Accounting for individual characteristics and the work environment. Cornell Hotel and Restaurant Administration Quarterly, 36(6), 36-42.

Walsh, K., \& Taylor, M. S. (2007). Developing in-house careers and retaining management talent: What hospitality professionals want from their jobs? Cornell Hotel and Restaurant Administration Quarterly, 48(2), 163-182.

\section{APPENDIX}

Training for cost-effectiveness vs. Using Training

As Tax Evasion Tool -Study on Private Companies of Bangladesh

\section{Instructions:}

Please Tick $(\sqrt{ })$ the answer of your choice or write in the space provided as the case may be.

1. Personal Demographic Information:

\begin{tabular}{|l|llll|l|}
\hline Gender & a) Male & b) Female & \\
\hline Job Level & a) Entry Level & b) Mid-Level & c) Top Level \\
\hline Job Experience & a) Less than 1-year & b) 1-4 years & c) 4-7 years & d) 7 years and above \\
\hline $\begin{array}{l}\text { No. of training } \\
\text { undergone }\end{array}$ & a) Never & b) 1-3 & c) 4-7 times & d) 7-10 times & e) 10 above \\
\hline
\end{tabular}

2. Why do you think you need to undergo training?

$\circ$ To get promotions

○ To get yourself updated for new technologies/skills and implement them

- If any other, please specify

O Or, you don't need training at all.

3. What are the important barriers to training in your organization?
O Time
○ Money
○ Lack of interest of management 
O Non-availability of skilled trainer

I If Others, please specify

4. What are the general complaints about the training session?
O Takes away precious time
O Training sessions are unplanned
O Boring and not useful
O Causes Cost
O Or any other, please specify

5. Is training fulfilling its objective?

O All the objectives are met

O Some objectives are met

O Met according to the need

O None of the objectives are me

6. There is noticeable development in job performance after training.

\begin{tabular}{|l|l|l|l|l|}
\hline Strongly agree & Agree & Neutral & Disagree & Strongly Disagree \\
\hline
\end{tabular}

7. Training improves overall performance of an organization.

\begin{tabular}{|l|l|l|l|l|}
\hline Strongly agree & Agree & Neutral & Disagree & Strongly Disagree \\
\hline
\end{tabular}

8. Training reduces errors / wastage

\begin{tabular}{|l|l|l|l|l|}
\hline Strongly agree & Agree & Neutral & Disagree & Strongly Disagree \\
\hline
\end{tabular}

9. Trainers are well competent and can get across their ideas.

\begin{tabular}{|l|l|l|l|l|}
\hline Strongly agree & Agree & Neutral & Disagree & Strongly Disagree \\
\hline
\end{tabular}

10. Training needs are identified through some specific mechanism in your organization.

\begin{tabular}{|l|l|l|l|l|}
\hline Strongly agree & Agree & Neutral & Disagree & Strongly Disagree \\
\hline
\end{tabular}

11. There are formal training evaluation methods to assess the effectiveness of the training

\begin{tabular}{|l|l|l|l|l|}
\hline Strongly agree & Agree & Neutral & Disagree & Strongly Disagree \\
\hline
\end{tabular}

12. Training programs are periodically evaluated and improved.

\begin{tabular}{|l|l|l|l|l|}
\hline Strongly agree & Agree & Neutral & Disagree & Strongly Disagree \\
\hline
\end{tabular}

13. The organization has a system for calculating the cost and benefit of training programs.

\begin{tabular}{|l|l|l|l|l|}
\hline Strongly agree & Agree & Neutral & Disagree & Strongly Disagree \\
\hline
\end{tabular}

14. The budget for training is sufficient in your organization.

\begin{tabular}{|l|l|l|l|l|}
\hline Strongly agree & Agree & Neutral & Disagree & Strongly Disagree \\
\hline
\end{tabular}

15. The budget for training is effectively and efficiently utilized.

\begin{tabular}{|l|l|l|l|l|}
\hline Strongly agree & Agree & Neutral & Disagree & Strongly Disagree \\
\hline
\end{tabular}

16. Your organization keeps increasing the budget for training every year.

\begin{tabular}{|l|l|l|l|l|}
\hline Strongly agree & Agree & Neutral & Disagree & Strongly Disagree \\
\hline
\end{tabular}

17. Organizations use training programs as a tax evasion tool by increasing the cost.

\begin{tabular}{|l|l|l|l|l|}
\hline Strongly agree & Agree & Neutral & Disagree & Strongly Disagree \\
\hline
\end{tabular}

18. Who are the trainers?

\begin{tabular}{|c|c|c|}
\hline Top level employees & Skilled employees of your organization & Professional trainers hired from Outside \\
\hline
\end{tabular}

Thank you for helping me and giving me your precious time. 